\title{
An Evaluation of Veterinary Production and Services in Bangladesh
}

\author{
Tonema Tabassum Prova ${ }^{1} \&$ Md. Hasanur Rahman ${ }^{2 *}$ \\ ${ }^{1}$ Department of Pharmacy, Comilla University, Cumilla-3506, Bangladesh \\ ${ }^{2}$ Department of Economics, Comilla University, Cumilla-3506, Bangladesh \\ *Corresponding Author: Email- hasanur.cou@gmail.com \\ https://riiopenjournals.com/index.php/society sustainability/index
}

Doi:https://doi.org/10.38157/society_sustainability.v3i1.288

Citation: Prova, T. T. \& Rahman, M. H. (2021). An Evaluation of Veterinary Production and Services in Bangladesh, Society \& Sustainability, 3(1), 52-66. Doi: https://doi.org/10.38157/society_sustainability.v3i1.288

\section{Research Note}

\begin{abstract}
As a developing country, the economy of Bangladesh is based on agricultural activities. Veterinary science and production have a significant impact on the socio-economic development of the country. The current study evaluates the sector in terms of Animal Feeds, Disease and Diagnostic Services, Preventive Veterinary Service, Clinical Service, Artificial Insemination, Wildlife Healthcare, Administrative Assistance, Legal framework and policy regime, Veterinary Public Health and Zoonoses, Research and Development for Veterinary Science, Licensing Veterinary Activities, Industrial Evaluation Based on ventures, and Veterinary education and research activities. Veterinary activities and economic development are positively correlated and affect poverty alleviation. The current study is a pioneering attempt to evaluate the area in the context of Bangladesh, which will essentially add value to the existing literature.
\end{abstract}

Keywords: Veterinary Science, Animal Husbandry, Veterinary Production, Bangladesh

\section{Introduction}

Veterinary science is the part of science that manages the causes, determination, and treatment of infections and wounds of living beings, most particularly domestic animals. According to Berendt et al. (2015), veterinary medication is concerned about the anticipation, control, analysis, and treatment of infections influencing the physical conditions of domestic and wild animals and with the prevention of transmission of the diseases to individuals. Veterinarians work to guarantee a protected food supply for individuals by observing and keeping up the health of food-delivering living beings. In Reality, it is the field that worries about the infections and wellbeing of all living species other than people (counting primates). It incorporates fields, for example, clinical practice, the safety of food-producing animals, animal-sourced food safety and quality, zoonosis, etiology, and the study of disease transmission. In Roman, the animal overseers were called "Souvetaurinarii", from which the word veterinaries may have later been 
inferred. Upon the separation of India and Pakistan in August 1947, a large number of the Muslim Veterinarians of West Bengal moved to East Bengal, (later on named, East Pakistan, presently Bangladesh). These Muslim Veterinarians set up a Veterinary school at the outskirts of Cumilla town in 1947 with a three-year diploma program known as DVMS (Doctor of Veterinary Medicine and Surgery). This course was later renamed LVS (Licentiate Veterinary Science). It was gradually expanded in terms of its scope and dimensions. Foundation of Veterinary Services in the country has experienced rapid expansion including animal feeds and medications both for the domestic and wild creatures, infection indicative clinical administrations, preventive measures, administrative works, etc. The government's policy aims to maximize those kinds of sub-potential sectors by fostering an enabling environment, expanding possibilities, and lowering risk and vulnerability. The private sector also played a significant role to develop those sub-sectors, while the Department of Livestock Services (DLS) and Bangladesh Livestock Research Institute (BLRI) have been played supportive roles. The transformation of veterinary science in Bangladesh is currently moderate yet not insignificant. From the beginning to now, the transformation is remarkable, and step by step the sector is expanding which prompts a promising future.

Given the gravity of the sector, the key aim of this study is to evaluate veterinary production and science in Bangladesh. Specifically, the study evaluates the sector in terms of Animal Feeds, Disease and Diagnostic Services, Preventive Veterinary Service, Clinical Service, Artificial Insemination, Wildlife Healthcare, Administrative Assistance, Legal framework and policy regime, Veterinary Public Health and Zoonoses, Research and Development for Veterinary Science, Licensing Veterinary Activities, Industrial Evaluation Based on ventures, and Veterinary education and research activities.

The study is based on the information from previous studies, case analyses, reports, and daily newspapers. Section 2 represents the brief historical background. Section 3 presents the literature review. The evaluation section has presented in section 4 and the summary of the evaluation has been presented in section 5 . The conclusion and recommendations have been presented in section 6 .

\section{Historical Background}

Atharvaveda is considered a store of primitive medications that contain a remedy for the treatment of sick animals. Veterinary science was well organized during the period of Ashoka, and the first veterinary hospital with indoor animal-keeping facilities was built during his reign (Schwabe, 1978). The main scholastic foundation, Bengal Veterinary Organization was set up in 1893 to give formal veterinary training in this part of the world. After the partition of the Indian continent, the principal Veterinary establishment was started in Cumilla, an eastern district of Bangladesh. The institution used to offer a three-year course called the Diploma of Veterinary medicine and Surgery (DVMS). The school was then moved to Tejgaon Dhaka and the course was renamed as Licentiate of Veterinary Specialist (LVS). During 1951-52 the first group of twelve students was enlisted for undertaking a 5-year bachelor course. In 1957-58 the veterinary school was moved to Mymensingh and the school kept on contributing both bachelor and 
certificate courses. Finally, the Bangladesh Agricultural University (BAU) was set up on the same college campus in 1961. After the foundation of College, two separate certificates named Doctor of Veterinary Medication (DVM) and B. Sc in Animal Husbandry were presented (DLS, 1998). Without thinking about the issues of the two bifurcated degrees offering from BAU on domesticated animals, four Government Veterinary universities have been set up in Bangladesh with a joint educational plan of Veterinary Science and Animal Husbandry (Animal Farming) and with five year DVM degree including one-year internship training. These Veterinary universities were set up at Sylhet (1994), Chittagong (1996), Dinajpur (2003), and Barishal (2003). Therefore, the four-year DVM, B.Sc. graduates of BAU, and five year DVM graduates including the internship program of Government Veterinary colleges created a new door in the education, employment generation, and working fields in the veterinary sector of Bangladesh. In 1989, Tamil Nadu Veterinary and Animal Sciences has been established in India, which helped to contribute to veterinary development and expansion all over the South Asian countries (Samad \& Ahmed, 2003).

As far as research is concerned, after the splitting of the subcontinent, Animal Husbandry Research Institute and Poultry Research Institutes were set up to direct research for the anticipation and control of poultry and domesticated animal infections on 26 November 1947 along with the foundation of the Veterinary Exploration Framework in Bangladesh (Kalam, 2013).

\section{Literature Review}

The existing literature has been reviewed to build the ideas and framework of this study. The result analysis and presentation of this study are based on the previous studies. Some important and relevant studies are presents in Table 1.

\section{Table 1: An illustrative list of studies on Veterinary Education and Research in Bangladesh}

\begin{tabular}{|l|l|}
\hline Authors & Major Findings \\
\hline Rahman \& Kabir (2013) & $\begin{array}{l}\text { The emphasis on veterinary education sufficiently increases food and social } \\
\text { safety in Bangladesh. }\end{array}$ \\
\hline Rahman et al. (2019) & $\begin{array}{l}\text { Veterinary hospitals and education increase productivity in agricultural } \\
\text { farming and increase the social standard. }\end{array}$ \\
\hline Sarker et al. (2018) & $\begin{array}{l}\text { Animal diseases vastly reduce the productivity level at the regional and } \\
\text { national levels Where sustainable veterinary education helps to reduce animal } \\
\text { disease. }\end{array}$ \\
\hline Alam et al. (2014) & $\begin{array}{l}\text { Veterinary training increases the self motives for employment generation and } \\
\text { also influences in case of unemployment reduction. }\end{array}$ \\
\hline Islam \& Kashem (1999) & $\begin{array}{l}\text { Ethno-veterinary medicine (EVM) plays an important role to increase } \\
\text { productivity by reducing the common diseases for the rural farmers in } \\
\text { Bangladesh. }\end{array}$ \\
\hline Karim et al. (2014) & $\begin{array}{l}\text { The productivity of household animal-plant has been increased by the activities } \\
\text { of a veterinary hospital in Bangladesh. }\end{array}$ \\
\hline Rahman et al. (2014) & $\begin{array}{l}\text { Agro Feed and agro-business contribute the social and economic development } \\
\text { by profit-taking and employment generations. }\end{array}$ \\
\hline
\end{tabular}




\section{Evaluations}

For the assessment of the ordered advancement of veterinary science in Bangladesh, different extensions and exercises under this area, come at one spot. As per the exercises found in Bangladesh, the uprising was dissected.

\subsection{Animal Feed}

Even though the veterinary market is straightforwardly identified and linked with a meat protein source of the country, simultaneously, this area is the most susceptible because of a continuous flare-up of avian influenza and the number of homesteads for the reason of periodical outbreaks leading to a decrease in the production. According to the data available in the poultry sites, the veterinary market size of Bangladesh is around 30,000 cores BDT (MoFLbd, 2019). The veterinary market involves, (a) Medication and Feeds additives, nutrition/Vitamins/supplements, including natural, non-biological, nutritional, pharmacological, and non-dietary feed added substances or enhancements, (b) Feed (Basically for poultry, aquatic, and big animals), (c) Domestic animals (incubator, reproducer or breeding farms, grant parent stock, parent stock, business poultry grange, meat especially beef fattening ranch, milk-producing cattle, pet animal), and (d) Hardware and machinery associated with this sector (Sen, 2012).

The veterinary science division of Bangladesh has discovered that the expansion and manufacturing of valuable feeds and foods, synchronization of feed production and accessibility to animals, fortify of feed processing limit, empowering the food milling system, preservation and improvement of new pasturage frameworks, moderation of environmental change effects, and domestic security to take care of wellbeing and quality feed import are a portion of the choices forward to the expanded supply of feeds and grains help expanded manufacturing and profitability of livestock in the nation (Huque \& Sarker, 2014). In the examination zone, significant feed for domesticated animals is rice straw and other harvest build-ups enhanced with minimal amounts of grain and oilseed by items and weeds from a crop field. The veterinary and agricultural business specialists accentuated to utilize their horticultural by-products as they were the primary hotspots for animal feed yet a few ranchers bought feed like wheat grain, polished rice, oilcake, and molasses for their animals. On a normal, the ranchers of a review territory discovered feed about $6.63 \mathrm{~kg}$ straw, $12.3 \mathrm{~kg}$ green grass, $0.60 \mathrm{~kg}$ rice polish, $0.25 \mathrm{~kg}$ wheat grain, and $0.23 \mathrm{~kg}$ oil cake every day for their domesticated animals. Feed hotspot for chicken and ducks is generally searching in the little and medium homesteads and comprises feeds from characteristic plants and animal origin (Hossen et al., 2008). To maintain the increasing demand for animal feeds, a consistent manufacturing system is needed. Modern technology should be applied to raise the quantity and quality of animal feeds (Wangchuk \& Dorji, 2008).

\subsection{Disease and Diagnostic Services (DDS)}

After the independence of Bangladesh in 1971, deficiency of veterinary health and medication care facilities were given importance to raise veterinary production. The regular diseases were 
Black Quarter (23.1\%) and Foot and Mouth disease (35\%), Ranikhet (40.3\%) and Fowlpox (33.6 $\%)$, goat PPR (28.6\%), and Diarrhea (38.7\%). About $65 \%$ of farms take treatment for their cattle and poultry and 35\% don't treat (Hossain et al., 2013). Farms on average spent about 6.95 US\$ for treating their domesticated animals and poultry consistently as the veterinary science areas were yet to acquainted with the nation, particularly in towns (MoFLbd, 2019).

At present, the FDILs have offices for microscopy, parasitological, and restricted bacteriological investigation where the research laboratories use Reverse Transcriptase Polymerase Chain Reaction Facilities to detect the disease agents. Whenever justified, FDILs send the test to reference labs. The Central disease research laboratory is the lead lab of DLS and has abilities of bacteriological, virological, and serological investigation. The research center has a Reverse Transcriptase Polymerase Chain Reaction provision for recognizable proof of various disease agents. The central diseases investigation laboratory facility sorts out schooling for field veterinarians about standard systems for foregather and allocation of tests and train and backing FDILs on lab diagnosis (Kalam, 2013).

However, for a superior future, the government has focused on targeted vaccination programs for improving resistance against a few infectious diseases. Veterinarians are given arrangements at central, territorial, and local regulatory levels to recognize infections, giving treatment and assuring guarantee that creature infectious prevention measures and control programs are being actualized as per the arrangements of the predominant legislation (Badruzzaman et al., 2015). Anyway, the Veterinary Public Health Unit of Research, Training \& Evaluation segment of the DLS is practically missing a viable collective program along with the Health Department and the National Institute of Preventive and Social Medicine (NIPSOM). Also, this unit is under planned, low budgeted, and doesn't have adequate personnel and absolute labor. Scantiness requirements of strategies, laws, guidelines, standards, and norms are significant limitations in the prevention and control of zoonotic diseases (Khatun et al., 2019).

\subsection{Preventive Veterinary Service}

Disease prevention is one of the significant commands of veterinary assistance. The veterinary assistance of Bangladesh principally depends on immunization and prophylaxis methods (on a restricted scale) to control animal diseases. DLS has major planning set up from the first immunization program and vaccine production to encourage the supply of animal antibodies at a lower cost to ranchers. Improvement of PPR, Infectious Bursal Disease (Gumboro Infection), Goat Pox, Salmonella infection from nearby places shows the instigations of immunization advancement from the past till now (Debnath et al., 1990; Rich \& Perry, 2011).

At Present, there is an expanding interest in deciding the effect of antibody advancements created by utilizing public funds, focused on global turn of events, and understanding the elements and associated determinants which are added to the achievements and effects of such vaccines. The advancement of a live antibody against East Coast fever, a tick-borne disease of cows brought about by Theileria Parva (Perry, 2016).

In Bangladesh, a veterinary specialist at the sub-area level said that they visited a couple of business agro-veterinary farms every day for Bird flu yet couldn't go house to house to check 
lawn poultry or visit patio raisers as a result of deficient staffing. Though every union should have at least one animal healthcare center, there is not in every segment. There are two staff; one is a VFA (Veterinary Field Associate), who performs immunization programs and gives essential preliminary and initial treatment to the animals, and the other is an FAAI (Field Assistants in Artificial Insemination), who just performs artificial impregnation. Yet, without VFA, FAAI additionally performs the duties of a VFA (Rimi et al., 2018).

Animal healthcare training could be the best strategy to instruct ranchers for clean administration practice and pre-emptive activities for turning away illnesses. DLS has some instructive activities through farmer training and correspondence materials however done principally as a responsive measure to contain disease outbreaks. The World Bank upheld the avian influenza project has delivered a decent number of preparing materials and conducted a media refinement workshop (Orubu et al., 2020).

\subsection{Clinical Service}

To give legitimate clinical administrations for Livestock and wildlife creatures Bangladesh Veterinary Council was first framed under Bangladesh Veterinary Council Act. in 1986. Bangladesh Veterinary Council Act was passed by the Parliament on 11-11-1986 to accommodate the constitution of the Bangladesh Veterinary Committee.

Formal clinical veterinary assistance is delivered principally from the Upazila level. The Upazila setup is the cutting edge (essential level) administration conveyance set up of DLS for giving clinical consideration among others. There are around 500 Upazilas/metro thanas in the country. The exercises embraced by this essential level of veterinary help are to give crowd/herd and individual-based clinical assistance. As the proper private veterinary help has not been advanced unequivocally in the country, public veterinary assistance has no choice to give clinical consideration at the community network level. Upazila veterinarians mostly rely upon the clinical highlights for diagnosis and further associated analysis. Nonetheless, opportunities are accessible for microscopy and necropsy of poultry at the Upazila level. On a normal 40-50 animals are dealt with every day in a veterinary medical clinic. Locale Veterinary Clinics are auxiliary level veterinary medical clinics of the nation with smaller than usual analytic lab offices. The central Veterinary Medical clinic gives clinical consideration where present-day indicative offices and experts are accessible (Sen, 2012).

\subsection{Artificial Insemination}

At present artificial insemination is expanding rapidly and it covers around 35 to $40 \%$ of cows in Bangladesh (MoFLbd, 2019). For improving the production potentiality and hereditary value of the International Journal of Science, this program is extending. Planned impregnation was not presented there at the principal time of newly conceived Bangladesh. Towards the end of the twentieth century, it has begun to walk towards advanced strategy. In Bangladesh, the conception rate is about $45.33 \%$ and $57.33 \%$ in steers (Das et al., 2007). The low fertilization rate and other conception files after artificial insemination (AI) can be influenced by the wellbeing status of the bull, semen assortment, protection, and transportation methodology and handling 
of semen during the targeted scheme, AI gun loading, appropriate heat detection, and artificial insemination at right time, insemination inappropriate uterine surrounding and keeping the procedure record. Limitation and capacity of AI expert or corresponding personnel and insemination strategy are additionally assumed a significant part for scant fertility indices (Koert et al., 2018).

In Bangladesh, the artificial insemination procedure has been utilized close around fifty years and consistently this program is broadened. Utilizing (AI) the productivity and conceptive performances of our steer's population have improved gradually from the start. Despite these favorable circumstances, this strategy isn't yet received by the ranchers of numerous regions in our nation. Be that as it may, the pace of disease was higher in regular administrations (25\%) than in artificial ones (1\%). Other than this pace of achievement of scientific knowledge along with A.I. isn't that much acceptable in the Upazila. The ideal number of the cross-reared castle has yet not been accomplished because of the absence of legitimate information, accessibility of specialized people, and rancher consciousness. If the appropriate measures are not taken to proceed with the achievement of the artificial insemination program, the domesticated animal sector will be hampered (Te Velde et al., 2002). In this way, the Government should make important strides and proper programs to prepare the ranchers to give information about the methods and focal points of effective artificial insemination to improve the current state of the domesticated animal sector. A joint exertion by BRAC and the public authority laborers into the field to prepare a chosen number of individuals on the best way to oversee manual artificial insemination gave a head start to the task. At first, 130 individuals were elected to be prepared as planned impregnation experts and till today, BRAC has prepared 2,141 manual AI professionals effectively. Few are standing by to begin their activities in the rural zones (BRAC, 2018).

Table 2: Artificial Insemination, Treatment, Vaccination and Training Revolution

\begin{tabular}{|l|l|l|l|l|l|l|l|l|}
\hline \multicolumn{1}{|c|}{ Function } & $\mathbf{2 0 0 4 - 0 5}$ & $\mathbf{2 0 0 5 - 0 6}$ & $\mathbf{2 0 0 6 - 0 7}$ & $\mathbf{2 0 0 7 - 0 8}$ & $\mathbf{2 0 0 8 - 0 9}$ & $\mathbf{2 0 0 9 - 1 0}$ & $\mathbf{2 0 1 0 - 1 1}$ & $\mathbf{2 0 1 1 - 1 2}$ \\
\hline $\begin{array}{l}\text { Artificial } \\
\text { Insemination of } \\
\text { Cattle }\end{array}$ & 14.22 & 15.96 & 17.83 & 18.10 & 20.00 & 22.70 & 24.42 & 16.58 \\
\hline $\begin{array}{l}\text { Treatment of } \\
\text { livestock }\end{array}$ & 194.92 & 194.91 & 287.94 & 296.30 & 275.25 & 374.68 & 496.60 & 300.97 \\
\hline $\begin{array}{l}\text { Vaccination of } \\
\text { Livestock and } \\
\text { Poultry }\end{array}$ & 2278 & 2142 & 2869 & 2447 & 2065 & 2391 & 2410 & 732.84 \\
\hline Training & 6.24 & 7.14 & 8.13 & 7.28 & 8.00 & 8.78 & 9.81 & 5.92 \\
\hline
\end{tabular}

Source: Department of Livestock Services, MoFLbd annual report, 2019.

\subsection{Wildlife Healthcare}

Veterinarians are involved for a long in the administration of hostage creatures in the name of zoos. Wildlife is the dominating unique branch of forestry under the service named Ministry of Forest and Environment. The forest department officials for treating feeble creatures in sanctuaries typically call college veterinarians. As of late, the wildlife section of the forestry office has begun to enlist veterinarians as natural life veterinarians. The wildlife veterinarians 
are liable for observing the health and associated matters of wild creatures present in reserved forests, sanctuaries, and safari parks (Chowdhury \& Koike, 2010). According to Samad \& Ahmed (2003), the essential activities of zoo veterinarians are to keep up the life of creatures on shows, and they also additionally requested for the prevention and control of zoonoses, the dietary facilities, immunizations named as vaccination, guidelines, the training and government assistance for the welfare of wild creatures.

For the improvement of the future of Bangladesh, World Health Organization (WHO) and World Organization for Animal Health (WOAH) are crossing over human and animal wellbeing experts in Dhaka, Bangladesh, for fortifying prevention, ailments, recognition, and control of illnesses among creatures and people. Further cycles will be done soon.

\subsection{Administrative Assistance}

The veterinary assistance of Bangladesh has satisfactory legitimate instruments to set out upon administrative exercises. The fundamental administrative instruments are Bangladesh Disease of Animal Act, 2005, Bangladesh Disease of Animal Rules, 2008, Bangladesh Animal and Animal Product Quarantine Act, 2005, Bangladesh Animal Slaughter and Meat Quality Control Act, 2011, and Bangladesh Fish and Animal Feed Act, 2010. Field veterinary help has offered the capacity to get data from the stakeholders, to proclaim contaminated region, enter and investigate suspected premises, gather samples, confiscate creatures and related items, annihilate infected animal products, enforce movement control, and file cases with evidence against any supposed breach of these instruments. The law has likewise made enrolment of farms, veterinary clinics, Artificial insemination centers, and veterinary diagnostic Laboratories mandatory (Biswas et al., 2006). To control and shield against infections of the domesticated animals coming from abroad and to guarantee general wellbeing, various laws like "Livestock Diseases Act-2005", "Fish and Cattle Feed Ordinance 2008", "Animal and Animal Product Quarantine Act 2005" have been enacted. Additionally, there is a policy called the "National Livestock Development Policy-2007" which provides the direction to implement these laws properly. "Fisheries and Livestock Feed Act-2010" has additionally been endorsed to ensure the quality of domesticated animal feed (Wangchuk \& Dorji, 2008).

\subsection{Legal framework and policy regime}

The government has a decent number of strategies and plans for guaranteeing an empowering climate to keep up the smooth development of domesticated animals (Alam et al., 2009). Bangladesh Livestock Development Policy, Bangladesh National Poultry Development Policy, 2008, Bangladesh Avian Influenza, and Pandemic Influenza Preparedness Plan, National Strategy and Action Plan for the Control of Canine Rabies. Last Draft of National Extension Policy, 2013, Slaughter Act - 2011, Animal Feed Act - 2010, Bangladesh Zoo Act, 2009 (Draft), National Poultry Development Policy, 2008, Animal Disease Rule-2008, Avian Influenza Compensation Strategy and Guidelines, 2008, National Livestock Development Policy, 2007, Animal Disease Act, 2005, Bangladesh Veterinary Practitioners Ordinance, 1982, Bengal Cruelty to Animals Act, 1920. 
FMD Control Strategy is under the process of endorsement now. The government has a remuneration program for avian flu-influenced ranches and a National Biosecurity Guideline for keeping up high security at the farm level. In the event of other acts and rules, individuals may trust a decent veterinary society in the future.

\subsection{Veterinary Public Health and Zoonoses}

Zoonotic diseases are those sicknesses that are normally communicated from animals (nonhuman) to humans. Increasingly farming that is more concentrated and the pet-keeping propensity bring about the expanded frequent potentiality of zoonoses. The Veterinary Public Health (VPH) is a part of general wellbeing exercises that gave the use of expert veterinary aptitudes, information, and assets to the assurance and improvement of human physical condition. VPH exercises include an assorted scope of capacities inside public health, which mirror the wide network of interests among veterinary and human medications. The main exercises are pointed towards the decreasing rate of zoonoses in people, in their wild animal stores, and financially significant livestock (Sur \& Zaman, 2008).

Food safety and zoonotic infectious prevention are two significant regions of veterinary exercises. DLS veterinarians working in the field level are commanded for abattoir checking and meat inspection under Bangladesh Animal Slaughter and Meat Quality Control Act, 2011. Alongside DLS field workplaces City Corporations and Municipalities are likewise commanded to regulate the clean issues from animal-originated food and wastage and for abattoir checking. The field veterinarians do ante-mortem and after-death examinations in butcher houses and small slaughter fields close to meat selling places in Bazar. Nonetheless, butchering happens normally in non-assigned spots without earlier examination from qualified veterinarians (Cripps, 2010).

The veterinary sectors are still extremely frail now in the vast majority of the districts and are reliant on DLS for playing out their assignment in the region of animal-originated food and food items inspection. Ungemach et al. (2006) demonstrate that the veterinary public health and microbiology sector is endowed with the command for administering the veterinary general wellbeing exercises which envelop more extensive fields of sanitation, food safety, and zoonotic infection prevention and control. In any case, this part is generally occupied with observation.

As it can be said, the collective endeavors among doctors and veterinarians in correspondence, sharing general health information, and research settings could do a lot to improve human and animal wellbeing. Much can be happened possible by instruction, and specifically by expanding the familiarity with various health experts, and encouraging correspondence and cooperation between veterinary, public health, and agricultural expert workforce. This will assist us towards drawing closer and control zoonotic infections in as proficient and successful a path, which could be expected under the circumstances (Islam, 2014).

\subsection{Research and Development for Veterinary Science}

Diseases of animals are contagious to humans and produce infections. Veterinary researchers have made commitments to the control of practically each of the diseases. The Animal Health 
Division of BLRI is meant for animal-wellbeing-related research. The Animal Public Division of BLRI is directing the research on significant transboundary animal diseases specially contagions like profoundly pathogenic avian flu, paste des petits ruminants, and Foot and Mouth Infection. The division is additionally researching neglected zoonosis like Bacillus anthracis. The division has recognized modest advancements for cost-effective detection of infections like Enzymelinked Immunosorbent Assay (ELISA) Procedure for simple identification of PPR and Rinderpest and minimal cost of hemolysin for complement fixation test. Antigens for detecting pullorum disease and Mycoplasma in poultry and a consolidated antibiotic serum therapy for treating PPR affected ruminants have also been advanced. BLRI has developed antibodies against PPR and Salmonella from nearby isolates. In expansion, BLRI besides conducts a serological survey against significant transboundary diseases specifically against FMD, PPR, and avian flu in ducks.

BAU has evolved the Gumboro antibody which is currently being produced and delivered by the DLS vaccine production department. Worldwide standard working has been followed in the field of zoonotic infections. They have been researching avian flu, Nipah, and Japanese Encephalitis. Bhuiyan et al. (2004) have led an insightful investigation about the information, demeanor, and practice of Bangladesh poultry farmers concerning the utilization of antimicrobials, synthetic substances, and so on and its impact on general wellbeing. Hoque et al. (2010) have done a broad investigation underscoring quick rural development growth for financial development and food security by empowering private area ventures in the creation of dairy, meat, and poultry through upgrading the upper hand of the animal's industry in Bangladesh. Hossain et al. (2013) have directed an investigation to assess the impacts of Mannan oligo-saccharides (MOS) and saccharomyces cerevisiae on the broiler ration for the yield and quality of grilled meat. The examination came about high return and quality of meat which is all right for human ingestion. Karim et al. (2014) has done an elaborated report about incorporated cultivating with fishes, prawn, vegetables, and grains around the year with or without entire family approaches guaranteeing food security and safety, creating diverse monetary exercises, and earnings for mass individuals of Bangladesh. Not long ago, an investigation by Rahman et al. (2017) has discovered that Brucella abortus is common in not only people but also in animals in Bangladesh. Molecular characterization of Staphylococcus aureus strains in bovine mastitis milk in Bangladesh is currently under investigation. Even though we have various associations for veterinary improvement there are a few issues of the manufacturing companies and organizations just as some outside natural factors that hamper the vast majority of the business (Hoque et al., 2018).

\subsection{Licensing Veterinary Activities}

Authorizing of veterinary medications is the mandate of drug administration under the Ministry of Health and Family welfare and DLS takes participation in the approved program as a concerned committee member. The drug administration has settled a veterinary cell for encouraging authorizing, licensing, and monitoring of veterinary drugs (Kalam, 2013). 
Bangladesh Veterinary Council was first established under the Bangladesh Veterinary Council Act in 1986. Bangladesh Veterinary Council Act was passed by the parliament on 11-11-1986 to accommodate the constitution of the Bangladesh Veterinary Council. This Board has its office placed nowhere other than Dhaka. The Committee is run by a President who is elected by the individuals from the Council among themselves. Veterinarian pupils began to claim for an official body in 1961 and in 1974 established the Bangladesh Veterinary Association to push their requirement. Bangladesh Veterinary Council was formed in 1982 through the section of the Bangladesh Veterinary Council Act in the Parliament of Bangladesh. It was qualified by the Bangladesh Veterinary Council Act in 2016. The committee was additionally changed through the Bangladesh Veterinary Council Bill 2019.

\subsection{Industrial Evaluation Based on ventures}

Veterinarians serve ventures like pharmaceuticals, biologicals, drug, organic, feed, and poultry at different limits including the board, management, field examinations, advertising, promoting, research, lab animal medication, specialized administrations, creation, and preparing any products, technical service, training, and manufacturing. The veterinarians in these ventures focus on those disorders of monetary significance that due to their etiology, the study of disease transmission meaning epidemiology is amiable to control counteraction or treatment or therapy with medications, synthetic chemical compounds, or biologicals (Samad \& Ahmed, 2003).

The extension of the activities of veterinary medication into the field of the health of the executives of farmed oceanic beings is unquestionably one of extraordinary potential. The advancement of expanded participation among veterinary disease transmission experts naming epidemiologist fish-health scientists and researchers and aqua-culturists will be commonly advantageous and, consequently, such cooperation should be started from all the associates included.

Following is an illustrative list of enterprises which make chiefly veterinary medications in the country:

i. A K International. 88/A Naya Pulton, Bangladesh

ii. ACI Limited. 245, Tejgaon Industrial Area, Bangladesh

iii. Advance Pharmaceuticals Ltd. 6F, Center Point concord, Farmgate, Bangladesh

iv. Agrosol Bangladesh Co.

v. Albatross agro-based Pvt. limited.

vi. BIOSCIENCE.

\subsection{Veterinary education and research activities}

The historical backdrop of veterinary schooling of Bangladesh is naturally interrelated with the veterinary institutions of the South Asian region. Priests of old times of this area were likely the main gathering of traditional healers and they were acknowledged about the therapeutic significance of spices, herbs, and crude drugs for the cure of diseases of steers (Somvanshi, 2006). During the English pioneer Colonial period, Hallen was appointed as the head of the cattle plague commission and he suggested the foundation of veterinary schools and following 
his proposals, Bengal Veterinary Institute was set up in 1893, which was the main scholarly establishment to give formal veterinary training in this part of the world. After the separation of India, the First Veterinary College was established in Comilla, an eastern district of Bangladesh. The College used to offer a three-year certificate course called the Diploma of Veterinary medicine and Surgery (DVMS). To fulfill the requirements for veterinarians to manage animal wellbeing and manufacturing issues, the Government of Bangladesh set up two veterinary Colleges in Sylhet and Chittagong which began offering 5-year bachelor courses along with a 1year internship in 1994 (DLS, 1998). Subsequently, 3 more veterinary colleges were set up with government activities in Dinajpur, Barishal, and Jhenaidah offering similar courses. The Chittagong Veterinary College was then redesigned into Chittagong Veterinary and Animal Science University and Sylhet Agricultural University replaced the Sylhet Veterinary College. The Dinajpur veterinary College was later incorporated into Haji Danesh Science and Technology University and Barisal Veterinary Collage to Patuakhali Science and Technology University as veterinary science faculties. Veterinary discipline was included in Rajshahi University, Bangabandhu Sheikh Mujibur Rahman Agriculture University, Gazipur, and in Sher-e-Bangla Agricultural University, Dhaka.

Following is the chronological development of veterinary education in Bangladesh.

i. Establishment of Bengal Veterinary Institute: (1893)

ii. Establishment of Veterinary College (1947) in Comilla

iii. The veterinary college shifted to Dhaka (1948)

iv. Introduction of graduation courses (1951-52) in the veterinary college located in Dhaka

v. The veterinary college shifted to Mymensingh (1957)

vi. Bangladesh Agricultural University started on the campus of the college of veterinary science and animal husbandry (1961)

vii. DVM degree and Animal Husbandry Degree were introduced (1961-62)

viii. Establishment of Sylhet and Chittagong Veterinary College to introduce coordinated degree (1995)

ix. Establishment of Chittagong Veterinary and Animal Science University (2005)

x. Establishment of different veterinary faculty or department in different universities.

\section{Summary of the evaluations}

From the assessment and investigation of veterinary science exercises in Bangladesh, it can be said that as an agriculture-based developing country, Bangladesh is advancing quickly in this area. Bangladesh is an agricultural country, and veterinary science is straightforwardly connected with it. So, the area should be widened more. On the other hand, the current extensions may be raised towards advanced levels in terms of process and types of equipment. Bangladesh has the option to embrace a decent arrangement of zoo sanitary laws and guidelines. Poultry and dairy farms may reach out to fisheries in a blend with horticulture.

\section{Conclusion and Recommendations}

The veterinary service of Bangladesh has a long custom but needs a change to meet the forthcoming demand of the century. Tragically, assessment of a large portion of the foods and 
products from animal origins is as yet performed by the non-veterinarians in Bangladesh which results in a repulsive output of human health to zoonotic diseases. The job of private and public veterinarians needs smoothing out, blended, and categorized. The public veterinary services ought to connect with their endeavors and energies in upholding those laws and control and monitor the private area to bring out the best from private area to help the general public. Veterinarians are yet to be acknowledged in biomedical research, drug organizations, pharmaceuticals, biotechnology, environmental science, natural life studies, wildlife studies, aqua, and fisheries and banking segments in Bangladesh. As of late, an enormous number of elite and skilled farmers have wandered into poultry and dairy cultivating in Bangladesh which upgraded the extent of veterinary medication yet veterinarians are not very much prepared to handle the prerequisite fieldwork. The educational programs and schedules of undergraduate veterinary educations are not just forward-thinking like developed and developing nations including neighboring countries, yet additionally, extraordinary contrasts exist among the degree offering institutions inside the nations (Rahman \& Majumder, 2020). To approach the goal of bringing equality with worldwide veterinary schooling and augment the extension for work inside and outside Bangladesh, it has become exceptionally demanding that educational plans and prospectuses for the undergraduate veterinary instruction in Bangladesh should be planned and carefully executed in all the degree offering colleges and universities in Bangladesh. The research center and the study of the Epidemiology network or organization should be fortified with the arrangement of higher preparation and satisfactory spending distribution. A National Animal Health Disease Control Committee (NAHDCC) should be shaped for framing practical strategies and operational recommendations to improve animal health circumstances in the nation drawing individuals from academic, research, and extension associations. Agents from NGOs, Private areas, Veterinary Council and Veterinary Associations should be part of the board of trustees. Exceptional measures should be taken to create networkbased veterinary service for giving quality competing flock and herd health administration by a qualified veterinarian. The government should give appropriate accentuation on reproductive health involving veterinarians in Animal Production Improvement Programmed and sanitation issues relating to animals, animal associates, and animal products. Local participation and joint efforts are required for the improvement of veterinary services throughout the country.

Author Contributions: Tonema Tabassum Prova deals with writing, analysis, and revision. Md. Hasanur Rahman provides general guidance, proofreading, and improved the draft.

Conflict of Interest: The authors declare no conflict of interest.

\section{REFERENCES}

Alam, M., Das, B. C., Hassan, M. M., Ahaduzzaman, M., Al Faruk, M. S., \& Hasanuzzaman, M. (2014). Ruminal acidosis-A case compilation study in SAQ Teaching Veterinary Hospital, Bangladesh. Veterinary World, 7(1). 38-43.

Ali, S. M. (1997). A brief resume of the development of veterinary education in East Pakistan (now Bangladesh). Bangladesh Veterinary Journal, 31, 1-7. 
Alam, G. M., Hoque, K. E., Khalifa, M. T. B., Siraj, S. B., \& Ghani, M. F. B. A. (2009). The role of agriculture education and training on agriculture economics and national development of Bangladesh. African Journal of Agricultural Research, 4(12), 1334-1350.

Badruzzaman, A. T. M., Siddiqui, M. S. I., Faruk, M. O., Lucky, N. S., Zinnah, M. A., Hossain, F. M. A., \& Rahman, M. M. (2015). Prevalence of infectious and non-infectious diseases in cattle population in Chittagong district of Bangladesh. International Journal of Biological Research, 3(1), 1-4.

Bangladesh Animal and Animal Product Quarantine Act, 2005 http://www.mofl.gov.bd

Bangladesh Animal Slaughter and Meat Quality Control Act, 2011 http://www.mofl.gov.bd

Berendt, M., Farquhar, R. G., Mandigers, P. J., Pakozdy, A., Bhatti, S. F., De Risio, L., \& Patterson, E. E. (2015). International veterinary epilepsy task force consensus report on epilepsy definition, classification, and terminology in companion animals. BMC veterinary research, 11(1), 1-11.

Bhuiyan, A. K. F. H., Bhuiyan, M. S. A., \& Deb, G. K. (2004). Indigenous chicken genetic resources in Bangladesh: Current status and future outlook. Animal Genetic Resources Information, 36, 73-100.

Biswas, P. K., Uddin, G. M. N., Barua, H., Roy, K., Biswas, D., Ahad, A., \& Debnath, N. C. (2006). Causes of loss of Sonali chickens on smallholder households in Bangladesh. Preventive Veterinary Medicine, 76(3-4), 185-195.

Chowdhury, M. S. H., \& Koike, M. (2010). Therapeutic use of plants by local communities in and around RemaKalenga Wildlife Sanctuary: implications for protected area management in Bangladesh. Agroforestry Systems, 80(2), 241-257.

Das, S.C., Chowdhury, S.D., Khatun, M.A., Nishibori, M., Isobel, N. \& Yoshimura, Y., (2007). Present scenario and future prospects of poultry production in Bangladesh. In Proceedings of the 5th International Poultry Show and Seminar (pp. 26-38).

Debnath, N. C., Sil, B. K., Selim, S. A., Prodhan, M. A. M., \& Howlader, M. M. R. (1990). A retrospective study of calf mortality and morbidity on smallholder traditional farms in Bangladesh. Preventive Veterinary Medicine, 9(1), 1-7.

Government of Bangladesh, (2007). National Livestock Development Policy, 2007 http://www.mofl.gov.bd

Koert, E., Harrison, C., Bunting, L., Gladwyn-Khan, M., \& Boivin, J. (2018). Causal explanations for lack of pregnancy applying the common sense model of illness representation to the fertility context. Psychology $\mathcal{E}$ Health, 33(10), 1284-1301.

Hossen, M. J., Hossain, M. S., Abedin, M. J., Karim, M. R., \& Rume, F. I. (2008). Animal production strategies in southern region of Bangladesh. The Agriculturists, 6(1\&2), 77-83.

Hossain, M., Ahmed, K., Marma, A. S. P., Hossain, S., Ali, M. A., Shamsuzzaman, A. K. M., \& Nishizono, A. (2013). A survey of the dog population in rural Bangladesh. Preventive veterinary medicine, 111(1-2), 134-138.

Hoque, M. N., Das, Z. C., Rahman, A. N. M. A., Haider, M. G., \& Islam, M. A. (2018). Molecular characterization of Staphylococcus aureus strains in bovine mastitis milk in Bangladesh. International Journal of Veterinary Science and Medicine, 6(1), 53-60.

Huque, K. S., \& Sarker, N. R. (2014). Feeds and feeding of livestock in Bangladesh: performance, constraints, and options forward. Bangladesh Journal of Animal Science, 43(1), 1-10.

Islam, M. A. (2014). Zoonoses in Bangladesh: the role of veterinarian in public health. Bangladesh Journal of Veterinary Medicine, 12(2), 93-98.

Islam, M. M., \& Kashem, M. A. (1999). Farmers' use of ethno veterinary medicine (EVM) in the rearing and management of livestock: An empirical study in Bangladesh. Journal of Sustainable Agriculture, 13(4), 39-56.

Kalam, M. A. (2013). Diversity of Veterinary Services in Bangladesh. Diversity of Veterinary Services in SAARC Countries, 37.

Khan, M. J. (2005). In-vitro and in-saceo evaluation of available feedstuff in Bangladesh. A project report, Ministry of Science, Information and Technology, Govt. of the People's Republic of Bangladesh.

Khatun, M. M., Islam, M. A., \& Rahman, M. M. (2019). Current status of veterinary public health activities in Bangladesh and its future plans. BMC veterinary research, 15(1), 1-5.

Karim, M. R., Parvin, M. S., Hossain, M. Z., Islam, M. T., \& Hussan, M. T. (2014). A report on clinical prevalence of diseases and disorders in cattle and goats at the Upazila veterinary hospital, Mohammad Pur, Magura. Bangladesh Journal of Veterinary Medicine, 12(1), 47-53. 
Orubu, E. S. F., Zaman, M. H., Rahman, M. T., \& Wirtz, V. J. (2020). Veterinary antimicrobial resistance containment in Bangladesh: Evaluating the national action plan and scoping the evidence on implementation. Journal of global antimicrobial resistance, 21, 105-115.

Perry, B. D. (2016). The control of East Coast fever of cattle by live parasite vaccination: A science-to-impact narrative. One Health, 2(12), 103-114.

Rahman, M. L., Mondal, M. N. \& Shahin, J. (2014). Evaluation of the Quality of Commercially Manufactured Fish Feeds used for Aquaculture in Bangladesh. International Journal of Applied Research and Studies, 3(2), 1-9

Rahman, M. A., Rahman, M. M., Abdullah, M. S., Sayeed, M. A., Rashid, M. H., Mahmud, R., \& Hoque, M. A. (2019). Epidemiological assessment of clinical poultry cases through the government veterinary hospitalbased passive surveillance system in Bangladesh: a case study. Tropical animal health and production, 51(4), 967-975.

Rahman, M. H., \& Majumder, S. C. (2020). Feasibility of NGO Initiatives in SME, Rural Benefits and Challenges: A Case Study in Cumilla, Bangladesh. Journal of Economic Info, 7(1), 26-39.

Rich, K. M., \& Perry, B. D. (2011). The economic and poverty impacts of animal diseases in developing countries: new roles, new demands for economics and epidemiology. Preventive veterinary medicine, 101(3-4), 133-147.

Rimi, N. A., Sultana, R., Ishtiak-Ahmed, K., Haider, N., Azziz-Baumgartner, E., Nahar, N., \& Luby, S. P. (2018). Where backyard poultry raisers seek care for sick poultry: implications for avian influenza prevention in Bangladesh. BMC Public Health, 18(1), 1-9.

Samad, M. A., \& Ahmed, M. U. (2003). History and scope of veterinary medicine. Bangladesh Journal of Veterinary Medicine, 1(1), 1-8.

Sarker, Y. A., Hasan, M. M., Paul, T. K., Rashid, S. Z., Alam, M. N., \& Sikder, M. H. (2018). Screening of antibiotic residues in chicken meat in Bangladesh by thin-layer chromatography. Journal of Advanced Veterinary and Animal Research, 5(2), 140-145.

Sen, B. K. Veterinary industry in Bangladesh: Present status and future potentials. Dhaka University Journal of Marketing, 15(6), 327-342.

Somvanshi, R. (2006). Veterinary medicine and animal keeping in ancient India. Asian Agri-History, 10(2), 133-146.

Sur, M., \& Zaman, Z. U. (2008). High-value agriculture in Bangladesh: as assessment of agro-business opportunities and constraints. The World Bank, No. 45760, 1-129.

Te Velde, H., Aarts, N., \& Van Woerkum, C. (2002). Dealing with ambivalence: farmers' and consumers' perceptions of animal welfare in livestock breeding. Journal of agricultural and environmental ethics, 15(2), 203-219.

Ungemach, F. R., Müller-Bahrdt, D., \& Abraham, G. (2006). Guidelines for prudent use of antimicrobials and their implications on antibiotic usage in veterinary medicine. International Journal of Medical Microbiology, 296(6), 33-38.

Wangchuk, K., \& Dorji, T. (2008). Animal feed production and management in Bhutan. Best Practices: Animal Feed Production and Management in SAARC Countries. Edited by AK Azad. SAARC publications December 2013, 71109.

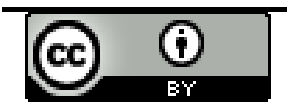

(c) 2021 by the authors. Licensee Research \& Innovation Initiative, Michigan, USA. This article is an open-access article distributed under the terms and conditions of the Creative Commons Attribution (CC-BY) license (http://creativecommons.org/licenses/by/4.0/). 